\title{
Performance Status and Its Changes Predict Outcome for Patients With Inoperable Stage III NSCLC Undergoing Multimodal Treatment
}

\author{
LUKAS KÄSMANN ${ }^{1,2,3}$, JULIAN TAUGNER ${ }^{1}$, CHUKWUKA EZE $^{1}$, OLARN ROENGVORAPHOJ ${ }^{1}$, \\ MAURICE DANTES ${ }^{1}$, KATHRIN GENNEN ${ }^{1}$, MONIKA KARIN ${ }^{1}$, OLEG PETRUKHNOV ${ }^{1}$, \\ AMANDA TUFMAN ${ }^{2,4}$, CLAUS BELKA ${ }^{1,2,3}$ and FARKHAD MANAPOV ${ }^{1,2,3}$ \\ ${ }^{1}$ Department of Radiation Oncology, University Hospital, LMU Munich, Munich, Germany; \\ ${ }^{2}$ Comprehensive Pneumology Center Munich (CPC-M), \\ Member of the German Center for Lung Research (DZL), Munich, Germany; \\ ${ }^{3}$ German Cancer Consortium (DKTK), Partner Site Munich, Munich, Germany; \\ ${ }^{4}$ Department of Pneumology, University Hospital, LMU Munich, Munich, Germany
}

\begin{abstract}
Background/Aim: Patient performance scores are used widely in clinical practice to assess a patient's general condition. The aim of this study was to evaluate the prognostic role of Eastern Cooperative Oncology Group performance score (ECOG PS) before, after and its changes during chemoradiotherapy in patients with stage III nonsmall cell lung cancer (NSCLC). Patients and Methods: Records of 99 patients with stage III NSCLC were evaluated. ECOG PS before, during and after chemoradiotherapy was analyzed for prognostic impact on overall (OS) and eventfree (EFS) survival. Results: Median OS considering the entire cohort was 20.8 months (range=15.3-26.2 months). Median $O S$, and 1- and 2-year survival rates were 26.4 months, $85 \%$ and $53 \%$ in patients with ECOG PS 0 versus 18.9 months, $69 \%$ and $37 \%$ in patients with ECOG PS 1 $(p=0.1, \log$-rank test $)$, respectively. After the first follow-up, $35 \%$ of patients presented worsening ECOG PS, while in $65 \%$ it was stable or improved. Median EFS according to ECOG PS 0, 1, 2 and 3 was 9.6, 9.0, 7.9 and 3.5 months, respectively, at the first follow-up ( $p=0.018$, log-rank test). Deterioration of ECOG PS after chemoradiotherapy resulted
\end{abstract}

The data were partly presented at the ESTRO and ELCC congress 2019.

Correspondence to: Lukas Käsmann MD, Department of Radiation Oncology, University Hospital, LMU Munich, Marchioninistrasse 15, 81377 Munich, Germany. Tel: +49 89440074511, Fax: +49 89440074523, e-mail: LKaesmann@gmail.com

Key Words: NSCLC, chemoradiotherapy, survival, prognostic factor, ECOG. in reduced $O S$ in the subgroups with initial ECOG PS $O$ and 1 ( $p=0.005$ and $p=0.001$, log-rank test). Conclusion: ECOG $P S$ and its changes have a strong impact on patient outcome. Deterioration of performance status was a strong negative prognostic factor for EFS and OS.

Lung cancer remains the leading cause of cancer-related mortality worldwide (1-4). Over $80 \%$ of all lung cancers are characterized as non-small cell lung cancer (NSCLC), mainly squamous cell carcinoma, adenocarcinoma and largecell carcinoma (3-5). Stage III NSCLC represents a locally advanced stage with heterogenous characteristics such as extensive lymph node (N3) involvement, large tumour volumes or infiltration of surrounding structures e.g. mediastinum, heart or spinal column $(3,4,6)$.

Karnofsky's performance status (KPS) or the Eastern Cooperative Oncology Group Performance Status Scale (ECOG PS) are widely used methods of assessing the functional status of cancer patients (7-11). Success of the individualized multimodal treatment highly depends on general and functional patient performance. A multimodal approach including chemo-, immunotherapy and locoregional thoracic irradiation is considered a standard of care in the treatment of inoperable stage III NSCLC. Patients with a good performance status (ECOG PS 0 or 1) should receive definitive concurrent chemoradiotherapy (CRT) followed by consolidation programmed cell death 1 ligand 1 (PD-L1) inhibition $(3,4,12$, 13). However, not all patients will be able to tolerate intensified multimodal approaches and understanding the role of patient performance during the course of treatment is necessary for personalized decision making. The aim of this retrospective study was to evaluate the prognostic role of ECOG PS before, during and after CRT in stage III NSCLC. 


\section{Patients and Methods}

Medical records of 99 patients consecutively treated with curativeintent multimodal treatment between December 2010 and December 2016 for stage IIIA/B NSCLC according to the seventh edition of the Union for International Cancer Control (UICC) classification were included (14). Pre-treatment evaluation included: patient history i.e. tobacco consumption, comorbidities, pulmonary function testing, radiographic imaging including computed tomography (CT) for all patients and positron-emission tomography (PET)-CT in $94 \%$, routine blood work to assess kidney, liver function and blood cell count.

Tumor histology was obtained via transbronchial biopsy in 80 patients, via CT-guided-biopsy in nine patients and with mediastinoscopy in 10. Therapeutic approach was discussed in Multidisciplinary Tumor Boards with. Informed consent was given by all patients for evaluation of the acquired data for research purposes. There was Ethical Committee approval for analysis and publishing of the patients' data (approval number: 17-230).

Treatment. Treatment was planned and delivered at one European tertiary cancer center. Three-dimensional (3D) conformal radiotherapy was delivered to the primary tumor and involved lymph nodes to a median total dose of 66 Gy (range $=45-70 \mathrm{~Gy}$ ). Elective nodal irradiation included directly adjacent nodal stations and was delivered to a total dose of $45-54 \mathrm{~Gy}$ to $85 \%$ of patients. Radiotherapy was delivered on a linear accelerator with megavoltage capability (6-15 MV) using 3D-CRT in $60 \%$ of patients and Intensity-modulated radiotherapy in $40 \%$ of patients. Image guidance was performed with cone-beam CT two or three times a week.

Patient follow-up. Local and locoregional progression and new distant metastases were documented with CT, PET-CT and magnetic resonance imaging scans. For the first 2 years after therapy, all patients underwent CT or PET-CT scans, routine blood work, lungfunction testing and clinical examination every 3 months, and afterwards twice a year. Event-free survival was calculated from the first day of radiation therapy.

Statistical analysis. All statistics were performed with IBM SPSS version 25 (IBM, Armonk, NY, USA). Survival curves were calculated with the Kaplan-Meier method and log-rank test (univariate analysis). Factors showing a significantly negative association with patient prognosis $(p<0.05)$ were included in multivariate analysis using Cox regression.

\section{Results}

A summary of patient and tumor characteristics is shown in Table I. The median survival was 20.8 months (range=15.326.2 months) in the entire patient cohort. Squamous cell carcinoma was diagnosed in $42 \%$ of patients, adenocarcinoma in $50 \%$ and not otherwise specified in $8 \%$ at initial diagnosis. The majority of patients were male $(63 \%)$ and the median age at diagnosis was 67.4 years (range $=43-88$ years). Overall, $56 \%$ of all patients had NSCLC stage IIIB according to the UICC (seventh edition). Patients were mostly diagnosed with T-stage $3(30 \%)$ or 4
(40\%) and N-stage $2(36 \%)$ or $3(45 \%)$. The majority of all patients $(78 \%)$ received concurrent CRT. The predominant concurrent chemotherapy regimen consisted of cisplatin given intravenously at a dose of $20 \mathrm{mg} / \mathrm{m}^{2}$ on days $1-4$ and oral vinorelbine (Navelbine) $50 \mathrm{mg} / \mathrm{m}^{2}$ on days 1,8 , and 15 , every 4 weeks for two courses (46\% of patients).

Patients with an initial ECOG PS 0 had a median OS of 26.4 months and an 1- and 2-year survival rate of $85 \%$ and $53 \%$ compared to patients with an ECOG PS 1 with a median OS of 18.9 months an 1- and 2-year survival rate of $69 \%$ and $37 \%$ ( $p=0.1, \log$-rank test) (see Table II). At the first follow-up after multimodal treatment, $34 \%$ of all patients had ECOG PS 0, 46\% ECOG PS 1, 18\% ECOG PS 2 and $2 \%$ ECOG PS 3. Median OS, 1- and 2-year survival rates were: 40.3 months, $88 \%$ and $64 \%$ in patients with ECOG PS 0 at the first follow-up; 19.3 months, $82 \%$ and $40 \%$ for ECOG PS 1; 11.9 months, $50 \%$ and $28 \%$ for ECOG PS 2; and 7.6 months, $0 \%$ and $0 \%$ for ECOG PS $3(p<0.001$, log-rank test), respectively. Decline of ECOG PS after multimodal treatment had a negative prognostic impact on OS in patients with initial ECOG PS 0 [median OS $19.1 \mathrm{vs}$. 31.4 months $(p=0.005, \log$-rank test)] and 1 [median OS 22.9 vs. 11.1 months $(p=0.001, \log$-rank test)]. In the multivariate analysis, male gender (hazard ratio $=1.964 ; 95 \%$ confidence interval $=1.201-3.211 ; p=0.007)$ and ECOG PS after treatment (hazard ratio $=1.67,95 \%$ confidence interval=1.082-2.577; $p=0.021$ ) achieved significance. Median EFS according to ECOG PS 0,1, 2 and 3 was 9.6, 9.0, 7.9 and 3.5 months at the first follow-up $(p=0.018$, logrank test). Deterioration of ECOG PS after CRT resulted in reduced EFS (median time 9.4 vs. 7.7 months, $p=0.049$, logrank test). No factor achieved significance in the multivariate analysis for EFS.

\section{Discussion}

Management of inoperable stage III NSCLC is very heterogeneous and may include different treatment modalities such as chemotherapy, locoregional thoracic irradiation, concurrent CRT, immunotherapy, targeted therapy and best supportive care depending on the performance status patient's $(3,4)$. As a result of the PACIFIC trial, concurrent platinum-based CRT followed by consolidation PD-L1 inhibition for over 1 year represents the actual standard of care for patients with inoperable stage III with good initial performance status (13).

In the real-life setting, not all patients will be able to tolerate and successfully complete such an intensified multimodal approach. In this situation, clinicians need to assess the suitability for the defined treatment approach continuously. Since their development 50 years ago, the KPS and ECOG PS have been established as standard simple assessment tools to determine the patient functional status 
Table I. Patient- and tumor-related characteristics.

\begin{tabular}{|c|c|c|c|}
\hline \multirow[t]{2}{*}{ Characteristic } & \multirow[t]{2}{*}{ Patients, n (\%) } & \multicolumn{2}{|c|}{ Initial ECOG PS, n (\%) } \\
\hline & & 0 & 1 \\
\hline \multicolumn{4}{|l|}{ Age } \\
\hline$\leq 65$ Years & $39(39 \%)$ & $26(67)$ & $12(31)$ \\
\hline$>65$ Years & $60(61 \%)$ & $21(35)$ & $39(65)$ \\
\hline \multicolumn{4}{|l|}{ Gender } \\
\hline Female & $37(37 \%)$ & $24(65)$ & $13(35)$ \\
\hline Male & $62(63 \%)$ & $23(37)$ & $38(61)$ \\
\hline \multicolumn{4}{|l|}{ T-Stage } \\
\hline $1-2$ & $28(28 \%)$ & $13(46)$ & $15(54)$ \\
\hline $3-4$ & $69(70 \%)$ & $32(46)$ & $36(52)$ \\
\hline \multicolumn{4}{|l|}{$\mathrm{N}$-Stage } \\
\hline $0-1$ & $19(19)$ & $7(37)$ & $12(63)$ \\
\hline $2-3$ & $80(81 \%)$ & $40(50)$ & $39(49)$ \\
\hline \multicolumn{4}{|l|}{ UICC stage } \\
\hline IIIA & $44(44 \%)$ & $17(39)$ & $27(61)$ \\
\hline IIIB & $55(56 \%)$ & $30(55)$ & $24(44)$ \\
\hline \multicolumn{4}{|l|}{ Histology } \\
\hline Squamous cell carcinoma & $42(42 \%)$ & $16(38)$ & $25(60)$ \\
\hline Adenocarcinoma & $49(50 \%)$ & $28(57)$ & $21(43)$ \\
\hline Not otherwise specified & $8(8 \%)$ & $3(38)$ & $5(63)$ \\
\hline \multicolumn{4}{|l|}{ Tobacco consumption } \\
\hline$\leq 40$ Pack years & $57(58 \%)$ & $31(54)$ & $25(44)$ \\
\hline$>40$ Pack years & $42(42 \%)$ & $16(38)$ & $26(62)$ \\
\hline \multicolumn{4}{|l|}{ Radiation dose } \\
\hline$\leq 60 \mathrm{~Gy}$ & $34(34 \%)$ & $12(35)$ & $22(65)$ \\
\hline$>60 \mathrm{~Gy}$ & $65(66 \%)$ & $35(54)$ & $29(45)$ \\
\hline \multicolumn{4}{|l|}{ ECOG PS after treatment } \\
\hline 0 & $33(33 \%)$ & $30(91)$ & $3(9)$ \\
\hline 1 & $45(46 \%)$ & $14(31)$ & $31(69)$ \\
\hline 2 & $18(18 \%)$ & $3(17)$ & $15(83)$ \\
\hline 3 & $2(2 \%)$ & $0(0)$ & $2(100)$ \\
\hline
\end{tabular}

ECOG PS: Eastern Cooperative Oncology Group performance score; UICC: Union for International Cancer Control.

(15, 16). KPS and ECOG PS have been shown to be correlated with response and tolerability to oncological treatment modalities, (overall) survival, and quality of life $(8,10,17,18)$. Assessing the patient's general condition with KPS or ECOG PS also has several limitations which need to be considered e.g. high interobserver variability and subjective scoring. Interestingly, according to the results of Buccheri et al., KPS showed less ability than ECOG PS to discriminate patients with different prognoses and therefore they recommended the usage of ECOG PS over KPS (19). Despite limitations, important clinical decisions are based on these performance scores, including a definition of personalized therapeutic approach and follow-up intensity as well as eligibility for clinical trials. A poor performance status is associated with increased risk for treatment-related toxicity and poor oncological outcomes compared to patients with better performance status (20). In our study, patients
Table II. Univariate analysis of overall survival.

\begin{tabular}{lccc}
\hline & \multicolumn{2}{c}{ Overall survival } & \\
\cline { 2 - 3 } Characteristic & $\begin{array}{c}\text { At } 12 \\
\text { months }(\%)\end{array}$ & $\begin{array}{c}\text { At } 36 \\
\text { months }(\%)\end{array}$ & \\
& & & \\
\hline Age & 69 & 36 & \\
$\quad \leq 65$ Years & 80 & 28 & 0.348 \\
$>65$ Years & & & \\
Gender & 87 & 48 & \\
Female & 70 & 22 & 0.007 \\
Male & & & \\
UICC stage & 77 & 40 & \\
IIIA & 75 & 25 & 0.23 \\
IIIB & & & \\
ECOG PS before treatment & 85 & 36 & \\
0 & 69 & 28 & 0.108 \\
1 & & & \\
ECOG PS after treatment & 88 & 55 & \\
0 & 82 & 22 & \\
1 & 50 & 17 & \\
2 & 0 & 0 & $<0.001$ \\
3 & & & \\
ECOG PS change & 64 & 40 & $<0.001$ \\
Stable & 62 & 12 & \\
Increase & & & \\
\hline
\end{tabular}

ECOG PS: Eastern Cooperative Oncology Group performance score; UICC: Union for International Cancer Control.

with an initial ECOG 0 showed an improved median survival of 26.4 months compared to patients with ECOG PS 1 with 18.9 months. After the administered CRT, the performance status differed widely from ECOG PS 0 (34\%), 1 (46\%), 2 (18\%) to 3 (2\% of all patients). This important finding might be explained by the acute side-effects of the administered multimodal treatment, individual patient ability to recover, and through the course of treated cancer (non-response $v s$. response to applied therapy). The majority of patients benefit during CRT due to effective symptom and tumor control. Based on treatment response, some patients experienced a significant improvement of their initial performance status.

The principal finding of the present study was that ECOG PS at the first follow-up after CRT was highly correlated with the median survival duration $(p<0.001)$. ECOG PS decline after multimodal treatment appears to be strong negative prognostic factor for OS in patients with initial ECOG PS of 0-1. Moreover, EFS was not affected by ECOG PS before multimodal treatment but was significantly impaired by decline of ECOG PS after CRT, with median time of $9.4 v s .7 .7$ months, respectively.

Several limitations of this study must be considered, such as the retrospective nature and, therefore, a risk of including hidden selection biases. Accurate scoring of 
performance status is of critical importance because decision-making needs to be based on its correct assessment, including the eligibility for and planning of clinical trials and allocation of healthcare resources such as palliative care. In our study, ECOG PS was scored by experienced radiation oncologists. However, we were unable to evaluate interobserver variability. Therefore, future studies need to prospectively confirm our findings and assess interobserver variations.

\section{Conclusion}

In inoperable stage III NSCLC, despite the prognostic value of the ECOG PS before multimodal treatment, ECOG PS after completion of CRT as well as its change during treatment application have a strong prognostic impact on patient OS and EFS.

\section{Conflicts of Interest}

The Authors have declared that there are no conflicts of interest with regard to this work.

\section{Authors' Contributions}

L.K., J.T., C.E., O.R., M.D., K.G., M.K., O.P., A.T., C.B. and F.M. contributed to the design and implementation of the research, L.K., J.T., C.E. and O.R. to the analysis of the results and L.K., J.T., C.E., O.R., and F.M. to the writing of the article.

\section{References}

1 Siegel RL, Miller KD and Jemal A: Cancer statistics. CA Cancer J Clin 69(1): 7-34, 2019. PMID: 30620402. DOI: 10.3322/ caac. 21551

2 Ferlay J, Soerjomataram I, Dikshit R, Eser S, Mathers C, Rebelo M, Parkin DM, Forman D and Bray F: Cancer incidence and mortality worldwide: sources, methods and major patterns in GLOBOCAN 2012. Int J Cancer 136(1): E359-E386, 2015. DOI: $10.1002 / \mathrm{ijc} .29210$

3 Ettinger DS, Aisner DL, Wood DE, Akerley W, Bauman J, Chang JY, Chirieac LR, D'Amico TA, Dilling TJ, Dobelbower M, Govindan R, Gubens MA, Hennon M, Horn L, Lackner RP, Lanuti M, Leal TA, Lilenbaum R, Lin J, Loo BW, Martins R, Otterson GA, Patel SP, Reckamp K, Riely GJ, Schild SE, Shapiro TA, Stevenson J, Swanson SJ, Tauer K, Yang SC, Gregory K and Hughes M: NCCN guidelines insights: non-small cell lung cancer, version 5.2018. J Natl Compr Canc Netw 16(7): 807-821, 2018. PMID: 30006423. DOI: 10.6004/jncen.2018. 0062

4 Postmus P, Kerr K, Oudkerk M, Senan S, Waller D, Vansteenkiste J, Escriu C and Peters S: Early and locally advanced non-small-cell lung cancer (NSCLC): ESMO Clinical Practice Guidelines for diagnosis, treatment and follow-up. Ann Oncol 28(suppl_4): iv1-iv21, 2017. PMID: 28881918. DOI: 10.1093/annonc/mdx222

5 Fujimoto J and Wistuba II: Current concepts on the molecular pathology of non-small cell lung carcinoma. Semin Diagn Pathol
31(4): 306-313, 2014. PMID: 25239274. DOI: 10.1053/j.semdp. 2014.06.008

6 Rami-Porta R, Asamura H, Travis WD and Rusch VW: Lung cancer - major changes in the American Joint Committee on Cancer Eighth Edition Cancer Staging Manual. CA Cancer J Clin 67(2): 138-155, 2017. PMID: 28140453. DOI: 10.3322/ caac. 21390

7 Collins JT, Noble S, Davies HE, Farewell D, Lester JF, Parry D and Byrne A: Performance status agreement assessed by the patient and clinician in a rapid access lung cancer service: Can either predict completion of treatment? Eur J Cancer Care 28(3): e13004, 2019. PMID: 30761639. DOI: 10.1111/ecc.13004

8 Kaesmann L, Janssen S and Rades D: Karnofsky performance score, radiation dose and nodal status predict survival of elderly patients irradiated for limited-disease smallcell lung cancer. Anticancer Res 36(8): 4177-4180, 2016. PMID: 27466528

9 Kaesmann L, Janssen S and Rades D: Prognostic factors including the expression of thyroid transcription factor 1 (TTF1) in patients irradiated for limited-disease small cell lung cancer. Anticancer Res 36(7): 3499-3503, 2016. PMID: 27354614.

10 Janssen S, Van Oorschot B, Käsmann L, Schild SE and Rades D: Validation of a score developed to estimate the 6-month survival of patients treated with palliative local radiotherapy for advanced lung cancer. Anticancer Res 37(7): 2537-2540, 2017. PMID: 27354614.

11 Bolm L, Janssen S, Kaesmann L, Wellner U, Bartscht T, Schild SE and Rades D: Predicting survival after irradiation of metastases from pancreatic cancer. Anticancer Res 35(7): 41054108, 2015. PMID: 26124362.

12 O'Rourke N, Roqué I Figuls M, Bernadó NF and Macbeth F: Concurrent chemoradiotherapy in non-small cell lung cancer. Cochrane Database Syst Rev 16(6): CD002140, 2010. PMID: 20556756. DOI: 10.1002/14651858.CD002140.pub3

13 Antonia SJ, Villegas A, Daniel D, Vicente D, Murakami S, Hui R, Kurata T, Chiappori A, Lee KH, de Wit M, Cho BC, Bourhaba M, Quantin X, Tokito T, Mekhail T, Planchard D, Kim YC, Karapetis CS, Hiret S, Ostoros G, Kubota K, Gray JE, PazAres L, de Castro Carpeño J, Faivre-Finn C, Reck M, Vansteenkiste J, Spigel DR, Wadsworth C, Melillo G, Taboada M, Dennis PA and Özgüroğlu M: Overall survival with durvalumab after chemoradiotherapy in stage III NSCLC. N Engl J Med 379(24): 2342-2350, 2018. PMID: 30280658. DOI: 10.1056/NEJMoa1809697

14 Mirsadraee S, Oswal D, Alizadeh Y, Caulo A and van Beek EJ: The 7th Lung Cancer TNM Classification and Staging System: Review of the changes and implications. World J Radiol 4(4): 128, 2012. PMID: 22590666. DOI: 10.4329/wjr.v4.i4.128

15 Oken MM, Creech RH, Tormey DC, Horton J, Davis TE, Mcfadden ET and Carbone PP: Toxicity and response criteria of the Eastern Cooperative Oncology Group. Am J Clin Oncol 5(6): 649-656, 1982. PMID: 7165009.

16 Karnofsky DA and Burchenal JH: The Clinical Evaluation of Chemotherapeutic Agents in Cancer. In: New York, Evaluation of Chemotherapeutic Agents. MacLeod CM (ed.). Columbia University Press, pp. 196-196, 1949.

17 Carey M, Bacon M, Tu D, Butler L, Bezjak A and Stuart G: The prognostic effects of performance status and quality of life scores on progression-free survival and overall survival in advanced ovarian cancer. Gynecol Oncol 108(1): 100-105, 2008. PMID: 17920108. DOI: 10.1016/j.ygyno.2007.08.088 
18 Moningi S, Walker AJ, Hsu CC, Reese JB, Wang J-Y, Fan KY, Rosati LM, Laheru DA, Weiss MJ, Wolfgang CL, Pawlik TM and Herman JM: Correlation of clinical stage and performance status with quality of life in patients seen in a pancreas multidisciplinary clinic. J Oncol Pract 11(2): e216-e221, 2015. PMID: 2556370. DOI: 10.1200/JOP.2014.000976

19 Buccheri G, Ferrigno D and Tamburini M: Karnofsky and ECOG performance status scoring in lung cancer: A prospective, longitudinal study of 536 patients from a single institution. Eur J Cancer 32(7): 1135-1141, 1996. PMID: 8758243.

20 Sargent DJ, Köhne CH, Sanoff HK, Bot BM, Seymour MT, De Gramont A, Porschen R, Saltz LB, Rougier P, Tournigand C,
Douillard JY, Stephens RJ, Grothey A and Goldberg RM: Pooled safety and efficacy analysis examining the effect of performance status on outcomes in nine first-line treatment trials using individual data from patients with metastatic colorectal cancer. J Clin Oncol 27(12): 1948, 2009. PMID: 19255311. DOI: 10.1200/JCO.2008.20.2879
Received July 3, 2019

Revised July 14, 2019

Accepted July 16, 2019 